\title{
Erratum to: Increased dietary levels of $\alpha$-linolenic acid inhibit mammary tumor growth and metastasis
}

\author{
Marianela Vara-Messler ${ }^{1,2,3}$ - Maria E. Pasqualini ${ }^{1,2} \cdot$ Andrea Comba $^{1,2}$. \\ Renata Silva $^{1,2}$ - Carola Buccellati $^{4} \cdot$ Annalisa Trenti $^{3} \cdot$ Lucia Trevisi $^{3}$. \\ Aldo R. Eynard ${ }^{1,2} \cdot$ Angelo Sala $^{4,5}$ - Chiara Bolego ${ }^{3}$ - Mirta A. Valentich ${ }^{1,2}$
}

Published online: 28 March 2016

(C) Springer-Verlag Berlin Heidelberg 2016

\section{Erratum to: Eur J Nutr \\ DOI 10.1007/s00394-015-1096-6}

The original article was published with an error in the article title. The word "linolenic acid" has been misspelled as "linoleic acid". The correct title should be: "Increased dietary levels of $\alpha$-linolenic acid inhibit mammary tumor growth and metastasis".

The online version of the original article can be found under doi:10.1007/s00394-015-1096-6.

\section{Mirta A. Valentich}

mirtavalentich@gmail.com

1 Instituto de Investigaciones en Ciencias de la Salud de Córdoba (INICSA-CONICET), Universidad Nacional de Córdoba, Enrique Barros s/n. Ciudad Universitaria, 5000 Córdoba, Argentina

2 Instituto de Biología Celular, Cátedra de Biología Celular, Histología y Embriología, Facultad de Ciencias Médicas, Universidad Nacional de Córdoba, Enrique Barros s/n. Ciudad Universitaria, 5000 Córdoba, Argentina

3 Department of Pharmaceutical and Pharmacological Sciences, University of Padua, Largo E. Meneghetti 2, 35131 Padua, Italy

4 Department of Pharmacological and Biomolecular Sciences, University of Milan, Via Balzaretti 9, 20133 Milan, Italy

5 Institute of Biomedicine and Molecular Immunology, Italian National Research Council, Via Ugo la Malfa 153, 90146 Palermo, Italy 